\section{Testing the applicability of a model of oral health-related quality of life}

\author{
Teste da aplicabilidade de um modelo de \\ qualidade de vida relacionada à saúde bucal
}

\section{Prueba de la aplicación de un modelo de calidad de vida relacionada con la salud oral}

\section{Abstract}

1 Universidade Federal do Rio Grande do Sul, Porto Alegre, Brasil.

Correspondence

C. M. Santos

Universidade Federal do Rio Grande do Sul. Rua Ramiro Barcellos 2492, Porto Alegre, RS 90030-003, Brasil. camilastaas@gmail.com
The aim of this study was to test Wilson \& Cleary's conceptual model of the direct and mediated pathways between clinical and non-clinical variables in relation to oral health-related quality of life. A random sample of 578 older people was evaluated. Wilson \& Cleary's conceptual model was tested using structural equations modeling including: biological variables, symp tom status, functional health, oral health perceptions, oral health-related quality of life. Oral health-related quality of life was assessed with the Oral Health Impact Profile-14 (OHIP-14). In the final model, edentulism was negatively correlated to dissatisfaction of appearance of their dental prostheses $(r=-0.25)$. Worse functional status was correlated with poor oral health perception ( $r=0.24)$. Being aged over $68(r=0.25)$, being a female $(r=0.39)$ and living in rural areas $(r=0.15)$ had a direct effect on the edentulism. Age had a direct effect on OHIP-14 ( $r=-0.15)$. There was an indirect effect of sex on OHIP-14 via functional status $(r=0.12)$. The present findings partially support Wilson \& Cleary's model framework.

Quality of Life; Oral Health; Aged
Camila Mello dos Santos 1

Roger Keller Celeste 1

Juliana Balbinot Hilgert 1

Fernando Neves Hugo ${ }^{1}$

\section{Resumo}

O objetivo foi testar as vias diretas e mediadas do modelo de Wilson \& Cleary entre as variáveis clínicas e não clínicas em relação à qualidade de vida relacionada à saúde bucal. Uma amostra aleatória de 578 idosos foi avaliada. O modelo de Wilson \& Cleary foi testado usando-se a modelagem de equações estruturais, incluindo: variáveis biológicas, sintomas, estado funcional, percepção da saúde bucal, qualidade de vida relacionada à saúde bucal. Qualidade de vida relacionada à saúde bucal foi avaliada com o Oral Health Impact Profile-14 (OHIP-14). No modelo final, o edentulismo foi negativamente correlacionado com a insatisfação da aparência das próteses dentárias $(r=-0,25)$. O pior estado funcional foi correlacionado com a pior percepção de saúde bucal $(r=0,24)$. Ter 68 ou mais anos de idade $(r=0,25)$, ser do sexo feminino $(r$ $=0,39)$ e viver em áreas rurais $(r=0,15)$ são $f a$ tores para um efeito direto sobre o edentulismo. $A$ idade apresentou um efeito direto no OHIP-14 $(r=-0,15)$. O sexo apresentou um efeito indireto no OHIP-14 via estado funcional $(r=0,12)$. Os resultados do estudo corroboram parcialmente com o modelo.

Qualidade de Vida; Saúde Bucal; Idoso 


\section{Introduction}

Among quality of life instruments, specific ones may better capture the impact of some diseases that are not otherwise captured by general quality of life instruments. Oral Health Related Quality of Life (OHRQoL) measures are an important aspect in this issue and there is an increased recognition of the importance of incorporating them in evaluations of oral health. OHRQoL has been defined as "the absence of negative impacts of oral conditions on social life and a positive sense of dentofacial self-confidence" 1 (p. 13), and assess the frequency andor severity of functional and psychosocial impacts associated with oral disorders 2 .

The theoretical model of Wilson \& Cleary 3 explicitly conceptualizes the pathways between traditional clinical variables and quality of life. Their model used as mediators: symptom status, functional health, general health perceptions. One study reported that worse patient's symptoms predicted a lower functional status; worse daily functioning predicted lower global oral health perceptions 4; however no quality of life and biological/clinical variables could be included in the model. Another study identified paths linking symptom status directly to general health perceptions and one path linking symptom status directly to quality of life 5 . In relation to OHRQoL, previous studies showed that more severe clinical signs predicted worse patient reported symptoms; that, in turn, were associated with a lower functional status as measured by OHRQoL; and lower OHRQoL predicted worse global oral health perceptions 6 .

Several oral health, health behavior and demographic factors have been associated with OHRQoL 7,8. Studies have reported association between OHRQoL and number of teeth, sex, geographic location of the participant's residence, chewing problems, and satisfaction with appearance of teeth in older people $8,9,10$. In addition, education and income have been associated with OHRQoL in older community-dwelling adults 11 . Previous studies have linked of the demographic and socioeconomic variables with the prevalence of edentulism 12,13.

A few studies tested the Wilson \& Cleary's model, incorporating variables such as age, and sex. One study found a path from age to functional status 5 . In addition, this study found that age was not related to measures of symptom status, general health perceptions, or quality of life 5 . Other study revealed a possible interaction effects of age on report of symptom status 14 . One study concluded that the effect of gender on quality of life was indirect through functional status and the direct effect of gender on quality of life was very small and non-significant 15 . However, there have been no studies that have tested the Wilson \& Cleary's model in relation to OHRQoL, incorporating variables as sex, age, and presence of natural teeth in elderly population. To facilitate effective interventions, it is necessary to understand the antecedents and consequents of OHRQoL and the pathways underlying it 6 . The aim of the study is to test Wilson \& Cleary's conceptual model of the direct and mediated pathways between clinical and nonclinical variables in relation to the oral healthrelated quality of life in community-dwelling older people.

\section{Methods}

This paper reports findings from a secondary analysis of data collected in a study of older persons in the city of Carlos Barbosa, Rio Grande do Sul State, Brazil.

\section{Population and sample}

Carlos Barbosa is a city located in Southern Brazil, 104 kilometers north of the capital of Rio Grande do Sul State. In 2000, the city had 20,519 inhabitants, of whom 2,167 were aged 60 and above. In 2004, the municipality produced a register of all persons aged 60 years or older, from which 983 non-institutionalized participants were randomly selected. Those who had moved away and died before contact was established were considered ineligible. After contact, 13 persons were restricted to bed at home, one person had been hospitalized, and 97 persons refused to participate. At the end, 872 individuals agreed to participate in the study. More information on sampling is presented elsewhere 16. Data collection involved faceto-face interviews conducted in the participants homes or in community clubhouses. In addition the Municipality provided dental offices to the dental examinations 16 .

\section{Measures}

Wilson \& Cleary's conceptual model links biological variables, symptom status, functional health, general health perceptions, quality of life, and nonmedical factors. The model also links individual and environment characteristics, which were not part of this analysis.

The measures chosen to operationalize Wilson \& Cleary's models 1 and 2 (Figure 1) are described below. Many variables were dichotomized due to small numbers and/or non-linear 
1a) Model 1: Wilson \& Cleary's model

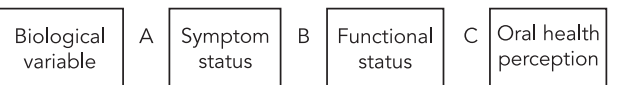

D

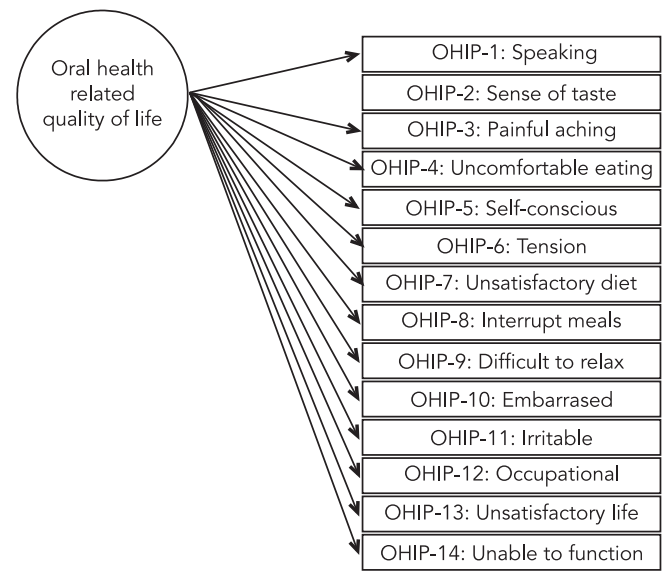

1b) Model 2: Wilson \& Cleary's model plus the demographic and socioeconomic variables

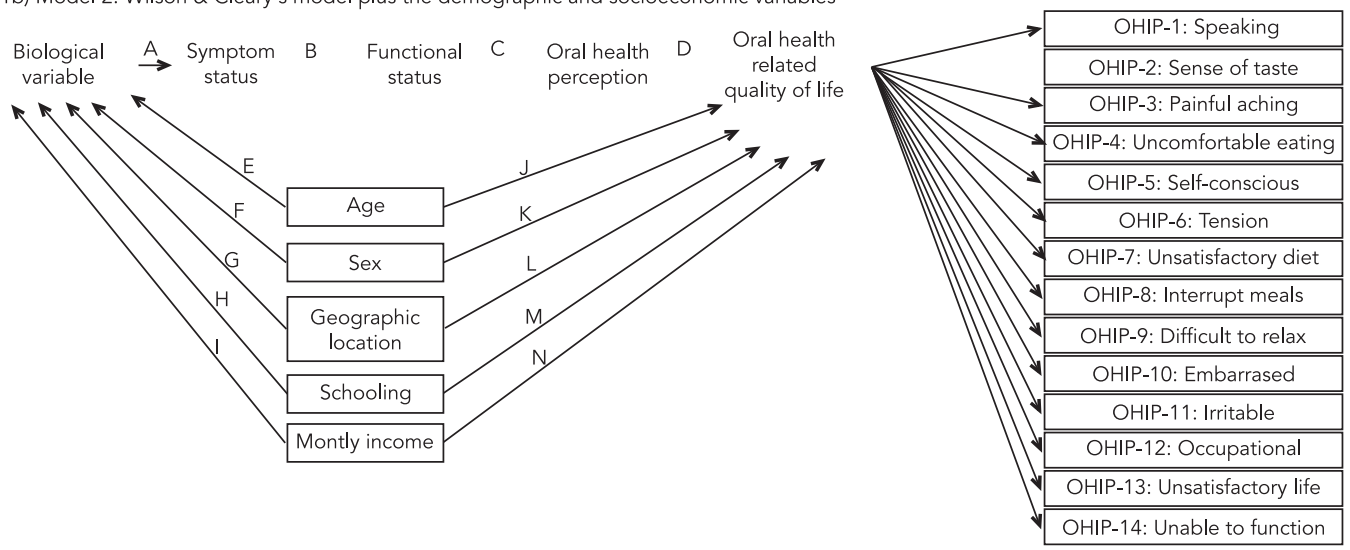

OHIP: Oral Health Impact Profile.

relationships. The non-linear relationship of dichotomized variables was observed in relation to the proposed outcomes in the initial model. The biological variable was edentulism (dentate $=$ 0 , edentulous $=1$ ) assessed by a clinical exam 17 . Symptom status was assessed using the question: "Are you satisfied with the appearance of your teeth or dental prostheses?". This question was assessed with four categories: very satisfied, satisfied, very dissatisfied, and dissatisfied; then dichotomized as very satisfied/satisfied as $0=$ satisfied and very dissatisfied/dissatisfied as $1=$ dissatisfied. Functional status was assessed using the question: "Have you decreased or changed the type and/or amount of food because of problems with your teeth or dental prostheses?". This question was assessed with three categories: nev- er, sometimes, and always; then categorized as never $=0$ and sometimes $/$ always $=1$. Oral health perception was measured using the question: "Compared with others your age, how would you rate the health of your mouth overall?”. Answers were initially selected from a 5-point Likert scale (excellent, very good, good, fair, and not good). The answers were categorized as excellent, very good or good as $0=$ good and as fair or poor as $1=$ not good. Oral health-related quality of life was assessed with the Oral Health Impact Profile-14 (OHIP-14). The OHIP-14 consists of 14 questions assessing the impact of oral problems in the perception of quality of life. The responses were classified through the Likert scale with five options ranging from "never" (0) to "very often" (4). The OHIP-14 scale score ranges from 0 to 5618 . 
The OHIP-14 scores were calculated by the additive method, with the response codes for the 14 items constituting the measure being summed up. The higher scores indicate more impacts meaning worse OHRQoL. The arrows in Figure 1 represent the hypothesized linkages between the variables tested in this analysis.

Wilson \& Cleary hypothesized pathways between non-adjacent levels. The measures chosen to operationalize Wilson \& Cleary's Model 2 are described below. The Model 2 was performed using the same variables used in the Wilson \& Cleary's Model 1 plus the demographic and socioeconomic variables (Figure 1). Participants were categorized as follows: age (in years, the mean age was 68 years, $0=<68$ years or $1=\geq 68$ years); sex $(0=$ male or $1=$ female); geographic location of the participant's residence $(0=$ urban or $1=$ rural); schooling (in years, $0=<4$ or $1=\geq$ 4) and monthly income (categorized using the Brazilian minimum wage during the data collection period as a reference, $0=\leq 118.00$ US dollars or $1=>118.00$ US dollars, i.e. one Brazilian minimum wage was equivalent to 118.00 US dollars). As hypothesized by Wilson \& Cleary, we predicted that biological variable would be related to the symptom status. This perceived symptom status would be related to functional status which, in turn, would be associated with oral health perception. The oral health perceptions would be related to OHRQoL. We hypothesized that demographic and socioeconomic variables would be related to biological variable and to OHRQoL.

\section{Statistical analysis}

Structural Equation Modeling (SEM) was used for the data analysis. SEM consists of two sub-models: the measurement model which establishes how the latent constructs are measured and the structural model which analyzes the structural relationships, corresponding to associations between variables. In this study, the latent construct of OHRQoL was measured by the OHIP-14. The OHIP-14 is a unidimensional scale 19. OHRQoL was modeled as a latent variable, and so it is represented as a circle in our figures. SEM was used to estimate the magnitude and direction of paths between the variables. The parameters of the models were estimated with Weighted Least Squares Means and Variances Adjusted Estimation (WLSMV). The standardized coefficients (SC) were interpreted according to Kline 20, where an SC of about 0.10 indicates a small effect, an SC of about 0.30 indicates a medium effect, and SC $>0.50$ indicates a strong effect. The interpretation of correlation between binary variables (tetrachoric correlations) follows the interpre- tation of ordinary correlation coefficient, such as Pearson's.

The goodness-of-fit of the model to the data was evaluated using the ordinary comparative parameters provided by the software. An overall conclusion about the fit of each model can be obtained by considering these indices simultaneously 21. Values under 0.05 for Root Mean Square Error of Approximation (RMSEA) suggest close approximate (adequate) fit, whereas values above 0.10 indicate poor fit. The Comparative Fit Index (CFI) and the Tucker-Lewis Index (TLI) represent incremental fit and values $>0.90$ are indicative of adequate fit. The Weighted Root Mean Square Residual (WRMR) is a measure for fit of models with categorical observed variables and a value less than 1.0 indicates good fit.

\section{Post hoc analysis}

Anticipating a possible model misfit and/or foreseeing plausible alternative for paths, the next step consisted in used the Modification Indices (MI). Changes suggested in MI were incorporated in the Model 2. MI indicates possible changes that could be made the model better "fit" the data. A MI reflects how much the overall model chisquare decreases if a constrained parameter is freely estimated. Here, MI values equal or above 10 were examined 22 , as well as the theoretical meaningfulness of the changes.

All analyses were performed using Mplus version 6.0 (Muthén \& Muthén, Los Angeles, USA) software for statistical analysis.

\section{Results}

Data from 578 elderly participants, with no missing data (66\% response rate), were analyzed in this study. In this sample, $67.3 \%$ were woman, the mean age was 68 years $( \pm 6.3), 53.5 \%$ were living in rural areas, $59.7 \%$ had received more than four years of schooling, and $46.7 \%$ had earnings above 118.00 US dollars at the time of data collection. The proportion of edentulous people was $57.6 \%$, while $20.6 \%$ were dissatisfied with the appearance of their teeth/prosthesis, $30.6 \%$ changed the type of food, $34.6 \%$ rated their health as regular/ poor. Regarding the latent variable, we also calculated OHIP14 scores, the mean values were 5.3 (standard deviation $= \pm 6.5, \min =0, \max =$ 37 ) and $76.3 \%$ of the individuals had at least one impact (score $>0$ ). Percentages for missing data (no response) are reported, $63.7 \%$ were woman, $56 \%$ aged $>68$ years, $49.3 \%$ were living in rural areas, $56 \%$ has $>4$ years of schooling, and $52 \%$ had earnings $>118.00$ US dollars at the time of 
data collection. There were no differences between the participants and those excluded for missing data.

Model 1 hypothesized that the associations between the main adjacent levels of the model would be the dominant pathways. In Model 1, we considered only these direct paths, as presented in Figure 1. Contrary to prediction, there was no direct association between biological variable and symptom status (Path A). Three of the direct paths were significant and with strong effect: symptom status-functional status (Path B), functional status-oral health perception (Path C) and oral health perception-OHRQoL (Path D). Fit indices for this model indicated that it did not fit the data well (Model 1 in Table 1).

Model 2 examined the direct and indirect pathways between distal variables and OHIP-14 (Figure 1). There was no direct effect between biological variable and symptom status (Path A), dissatisfaction with symptom status were associated with worse functional status (Path B), worse functioning predicted a poor oral health perception (Path C) and poor oral health perception was associated with higher scores in the OHIP-14 (Path D), indicating worse oral health quality of life. There were three significant direct paths leading to the biological variable (edentulism): age (Path E), sex (Path F) and geographic location (Path G). There were two significant direct paths leading to oral health quality of life: age (Path J) and sex (Path K). Fit indices for this model indicated that it improved, but one fit index (WRMSEA) was still not good enough (Model 2 in Table 1). Therefore, the next step was to determine whether a model incorporating the modification indices would fit the data better.

In the Final model (Figure 2), there was negative and significant direct effect between biological variable and symptom status (Path A). There was no direct association between symptom status and functional status (Path B). The worse functional status was associated with poor oral health perception (Path C). There was no direct association between oral health perception and oral health quality of life (Path D). Age (Path E), sex (Path F) and geographic location (Path G) had a significant direct effect on the biological variable. Age had a significant association with lower scores in the OHIP-14, indicating better oral health quality of life (Path J). There were five additional pathways in the Final model. The worse functional status was associated with higher scores in the OHIP-14, indicating worse oral health quality of life. The correlation between of the measurement errors OHIP-5 (self-conscious) and OHIP-6 (tension) was significant and of high magnitude. The worse symptom status was asso- ciated with poor oral health perception. The correlation between symptom status and oral health quality of life was significant and of moderated magnitude. Sex had a significant association with functional status. There was an indirect effect of sex on OHRQoL via functional status $(0.25 \times 0.49=$ 0.12). The Final model showed adequate fit (Final model in Table 1).

\section{Discussion}

This is one of the first studies that tested Wilson \& Cleary's model in oral health. The Final model presented a good fit, and the hypothesis that demographic variables (sex and age) would be related to edentulism and to oral health-related quality of life, was confirmed. Age and sex had a direct effect on the edentulism and on oral health-related quality of life. There was an indirect effect of sex on oral health-related quality of life via functional status, but not through health perception (not statistically significant).

Most SEM studies testing Wilson \& Cleary's model presented acceptable fit indexes $5,6,14,23,24,25,26,27$; therefore the validity of models has to concentrate on the plausibility associations and the direct and indirect effects of the variables. In our study, most distal (exogenous) variables had no indirect effect because the last pathway (from general health perceptions to quality of life) was closed (small and not significant effect). Three studies showed a significant direct effect between health perceptions and quality of life $14,24,25$, but other two did not found a relationship between those variables 6,26 . One explanation is lack of comparability, but the mix of results may point to lack of robustness of the model as well.

In our Final model, there was no statistically significant relationship between edentulism and OHRQoL. Also, other studies that tested Wilson and Clear model also found an association between the biological and symptom levels 5,27. On the other hand, it was associated with symptom status (satisfaction with appearance) in the present study. Hugo et al. also found that edentulous subjects rated their dental appearance good more frequently than dentate subjects 12 ; maybe because older persons believe that tooth extraction and full mouth extraction are procedures to eliminate and prevent toothache. Furthermore, the influence of fatalistic beliefs about the inevitable loss of teeth with age may negatively influence the acceptance of the consequences of tooth loss as detrimental to health, and any intervention to retain teeth may simply be perceived as ineffective 13 . Andrade et al. 28 found 
Table 1

Standardized coefficients of direct, indirect and total effect, and fit indices of the structural equation models.

\begin{tabular}{|c|c|c|c|}
\hline Pathway & Model 1 & Model 2 & Final model \\
\hline \multicolumn{4}{|l|}{ Direct effect } \\
\hline A: Biological variable $\rightarrow$ Symptom status & -0.04 & -0.10 & -0.25 * \\
\hline B: Symptom status $\rightarrow$ Functional status & 0.62 * & 0.58 * & 0.10 \\
\hline C: Functional status $\rightarrow$ Oral health perception & 0.86 * & 0.86 * & 0.24 * \\
\hline D: Oral health perception $\rightarrow$ Oral health quality of life & 0.52 * & 0.49 * & 0.06 \\
\hline $\mathrm{E}:$ Age $\rightarrow$ Biological variable & & 0.24 * & 0.25 * \\
\hline F: Sex $\rightarrow$ Biological variable & & 0.40 * & 0.39 * \\
\hline G: Geographic location $\rightarrow$ Biological variable & & 0.14 * & $0.15^{*}$ \\
\hline $\mathrm{H}$ : Schooling $\rightarrow$ Biological variable & & -0.10 & \\
\hline I: Monthly income $\rightarrow$ Biological variable & & -0.07 & \\
\hline $\mathrm{J}:$ Age $\rightarrow$ Oral health quality of life & & $-0.15 *$ & -0.15 * \\
\hline K: Sex $\rightarrow$ Oral health quality of life & & 0.17 * & 0.17 * \\
\hline L: Geographic location $\rightarrow$ Oral health quality of life & & -0.08 & \\
\hline M: Schooling $\rightarrow$ Oral health quality of life & & 0.00 & \\
\hline $\mathrm{N}:$ Monthly income $\rightarrow$ Oral health quality of life & & 0.02 & \\
\hline \multicolumn{4}{|l|}{ Indirect and total effects of distal variables } \\
\hline \multicolumn{4}{|l|}{ Age $\rightarrow$ Oral health quality of life } \\
\hline Indirect & & & 0.00 \\
\hline Total & & & -0.15 * \\
\hline \multicolumn{4}{|l|}{ Sex $\rightarrow$ Oral health quality of life } \\
\hline Indirect & & & -0.01 \\
\hline Total & & & 0.16 * \\
\hline \multicolumn{4}{|l|}{ Geographic location $\rightarrow$ Oral health quality of life } \\
\hline Indirect & & & 0.00 \\
\hline Total & & & -0.08 \\
\hline \multicolumn{4}{|l|}{ Schooling $\rightarrow$ Oral health quality of life } \\
\hline Indirect & & 0.00 & \\
\hline Total & & 0.00 & \\
\hline \multicolumn{4}{|l|}{ Monthly income $\rightarrow$ Oral health quality of life } \\
\hline Indirect & & 0.00 & \\
\hline Total & & 0.02 & \\
\hline \multicolumn{4}{|l|}{ Modification indices } \\
\hline Functional status $\rightarrow$ Oral health quality of life & & & 0.49 * \\
\hline OHIP-5 (self-conscious) $\rightarrow$ OHIP-6 (tension) & & & 0.74 * \\
\hline Symptom status $\rightarrow$ Oral health perception & & & 0.49 * \\
\hline Symptom status $\rightarrow$ Oral health quality of life & & & 0.40 * \\
\hline Sex $\rightarrow$ Functional status & & & 0.25 * \\
\hline \multicolumn{4}{|l|}{ Fit indices } \\
\hline $\mathrm{CFI}$ & 0.96 & 0.95 & 0.98 \\
\hline TLI & 0.95 & 0.94 & 0.98 \\
\hline RMSEA & 0.06 & 0.05 & 0.03 \\
\hline WRMR & 1.34 & 1.24 & 0.90 \\
\hline
\end{tabular}

CFI: Comparative Fit Index ; RMSEA: Root Mean Square Error of Approximation; TLI: Tucker-Lewis Index; WRMR: Weighted Root Mean Square Residual.

Model 1: Wilson \& Cleary's model modified with direct pathways between each of the adjacent main five levels; Model 2: Wilson \& Cleary's model modified plus the demographic and socioeconomic variables; Final model (parsimonious model): multiple direct and indirect effects model.

${ }^{*} p<0.05$. 
Figure 2

Final model.

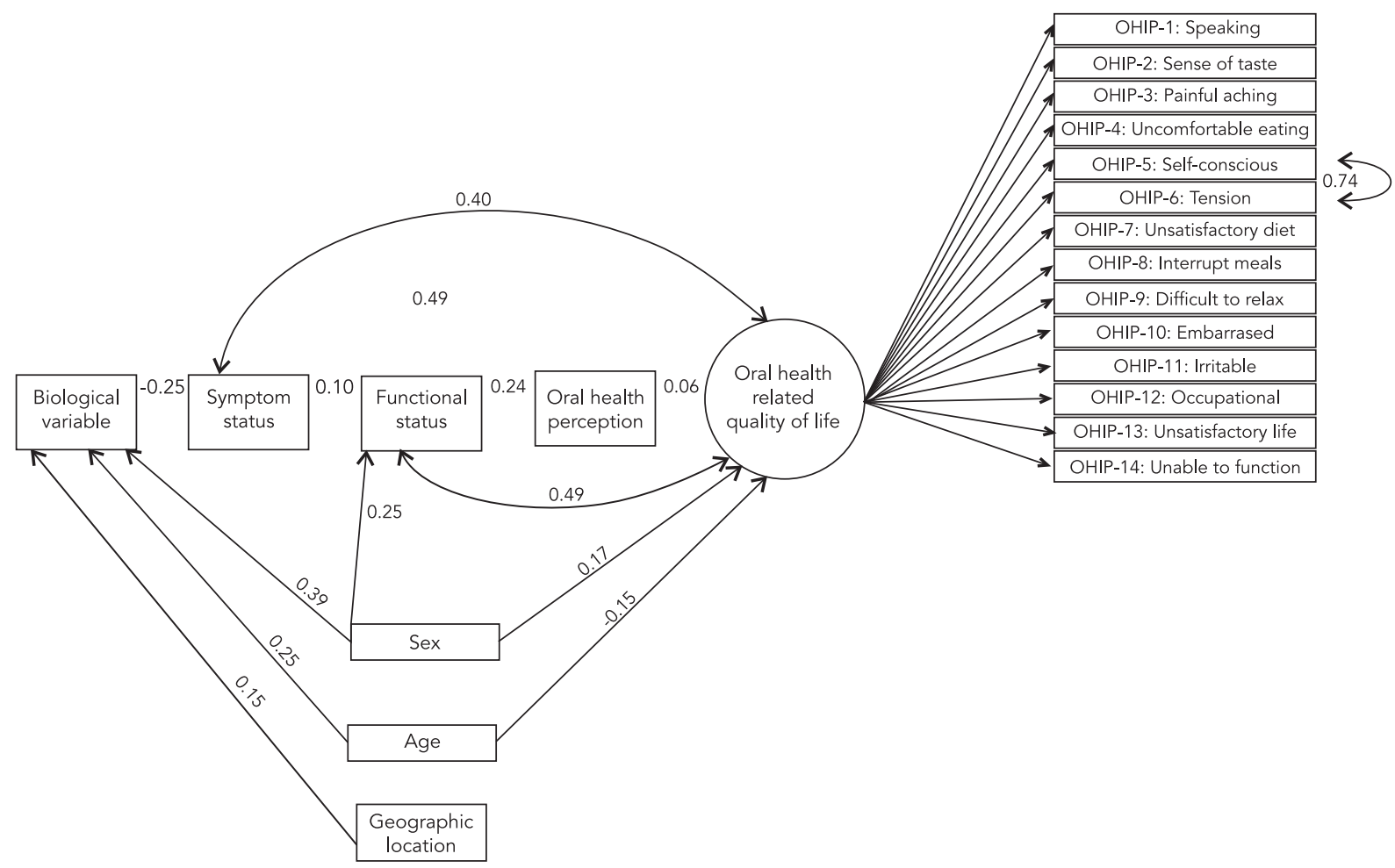

OHIP: Oral Health Impact Profile.

that poor self-rated oral health is associated with general health factors and the psychosocial impact of oral health on quality of life, regardless of socioeconomic and clinical health measures.

There were additional pathways in the Final model regarding age-edentulism and ageOHRQoL. Age was associated (direct or indirectly) with measures of quality of life in some studies 5,14,27, but not in another 26 . Our result is consistent with some previous studies where aged subjects were more prone to have fewer teeth 12,29. Also, participants aged $>68$ years had lower OHIP-14 scores indicating better OHRQoL. This result is in agreement with the findings reported by Jain et al. 30 , that the impact of oral health problems on the quality of life reduces with the increase of age. The older people evaluated in this study lived in a period in which edentulism and poor oral health seemed to have been considered a part of "normal” ageing 8,31.

In addition, there were two direct effects of sex on edentulism and on functional status. Fe- male gender was associated with edentulism and with poor functional status, confirming previous findings from the literature 12,13. Female subjects lose more teeth because they are more sensitive to their dental needs, experiencing more tooth loss from intervention and services 12 . This result is in accordance with the literature from a qualitative study suggesting that older women may be more vulnerable to tooth loss as a result of norms and beliefs 13 . In this study, there was an indirect effect of sex on OHRQoL via functional status $(0.25 \times 0.49=0.12)$. This suggests that women had worse OHRQoL because they had poor functional status, that is they had to change the type and/or amount of food. Additionally, there was a direct effect of sex on OHRQoL. This finding is supported by a study that showed that OHRQoL was poorer in women than in men ${ }^{32}$. This study showed the importance of the variable sex on OHRQoL. This can help in assessing and modifying theoretical models and has great potential for further theory development. 
Limitations of the present study include the generalizability of the results mainly because of the homogenous characteristics of the sample. Moreover, the Wilson \& Cleary's model is a conceptual model, sometimes difficult to operationalize. Another limitation of this study was that the use and the need of dental prosthesis were not assessed as mediating variables. The use of dental prosthesis is likely to be a strong mediator of edentulism and OHRQoL. Choosing the correct measurements has important theoretical and practical implications. Currently, there are no standardized measurements at each level/concept. For example, one study measured symptom status using the Xerostomia Inventory 6 , other as chewing difficulty, eating impact and perceptions of symptoms of dry mouth 4 , another using the Sign and Symptom Checklist for Per- sons with HIV 24, and another as a combination of seven subscales of Norwegian Version of the Abbreviated Burn-Specific Health Scale (BSHSN) and Medical Outcomes Study Short Form-36 (SF-36) 26.

In conclusion, the present study demonstrates that there are direct and mediated pathways between clinical and nonclinical variables in relation to OHRQoL in community-dwelling older people. The findings partially support Wilson \& Cleary's model framework, as some pathways were confirmed but other were closed. The inclusion of changes based on modification indices implies a rejection of the initial model. Future research should explore sociodemographic characteristics of the individual and the environment, as well as evaluate appropriate measures for each level/concept.

\section{Resumen}

El objetivo fue probar vías directas y medidores de Wilson \& Cleary para establecer las variables clínicas y no clínicas, en relación con la calidad de vida referente a la salud oral. Se evaluó una muestra aleatoria de 578 personas de edad avanzada. El modelo de Wilson \& Cleary fue probado usando modelos de ecuaciones estructurales, incluyendo: variables biológicas, síntomas, estado funcional, percepción de salud oral, calidad de vida relacionada con la salud oral. La calidad de vida se evaluó con el Oral Health Impact Profile-14 (OHIP-14). En el modelo final, el edentulismo se correlacionó negativamente con la insatisfacción de la aparición de las prótesis dentales $(r=-0.25)$. El peor estado funcional se correlacionó con una peor salud oral percibida $(r=0,24)$. Tener 68 años o más $(r=0,25)$, ser mujer $(r=0,39)$ y vivir en un área rural $(r=0,15)$ tuvo un efecto directo sobre edentulismo. La edad tuvo un efecto directo sobre la OHIP-14 $(r=-0.15)$. El sexo tuvo un efecto indirecto sobre la OHIP-14, a través del estado funcional $(r=0,12)$. Los resultados del estudio corroboran parcialmente el modelo.

Calidad de Vida; Salud Bucal; Anciano

\section{Contributors}

C. M. Santos, R. K. Celeste, J. B. Hilgert and F. N. Hugo contributed to study design, data collection and analysis, writing this article and approval of the final version for publication. 


\section{References}

1. Atchison KA. Understanding the quality in quality care and quality of life. In: Inglehart MR, Bagramian RA, editors. Oral health-related quality of life Hanover Park: Quintessence Books; 2002. p. 21-30.

2. Tsakos G, Allen PF, Steele JG, Locker D. Interpreting oral health-related quality of life data. Community Dent Oral Epidemiol 2012; 40:193-200.

3. Wilson IB, Cleary PD. Linking clinical variables with health-related quality of life: a conceptual model of patient outcomes. JAMA 1995; 273:59-65.

4. Baker SR, Pearson NK, Robinson PG. Testing the applicability of a conceptual model of oral health in housebound edentulous older people. Community Dent Oral Epidemiol 2008; 36:237-48.

5. Henderson WA, Martino AC, Kitamura N, Kim KH, Erlen JA. Symptom status predicts patient outcomes in persons with HIV and comorbid liver disease. AIDS Res Treat 2012; 2012:169645.

6. Baker SR, Pankhurst CL, Robinson PG. Testing relationships between clinical and non-clinical variables in xerostomia: a structural equation model of oral health-related quality of life. Qual Life Res 2007; 16:297-308.

7. Mason J, Pearce MS, Walls AW, Parker L, Steele JG. How do factors at different stages of the lifecourse contribute to oral-health-related quality of life in middle age for men and women? J Dent Res 2006; 85:257-61.

8. Santos CM, Martins AB, Marchi RJ, Hilgert JB, Hugo FN, Padilha DM. Assessing changes in oral health-related quality of life and its factors in community-dwelling older Brazilians. Gerodontology 2013; 30:176-86

9. Inukai M, John MT, Igarashi Y, Baba K. Association between perceived chewing ability and oral health-related quality of life in partially dentate patients. Health Qual Life Outcomes 2010; 19:118.

10. Stenman U, Ahlqwist M, Bjorkelund C, Hakeberg M. Oral health-related quality of life: associations with oral health and conditions in Swedish 70-year-old individuals. Gerodontology 2012; 29:440-6.

11. Makhija SK, Gilbert GH, Boykin MJ, Litaker MS, Allman RM. The relationship between sociodemographic factors and oral health-related quality of life in dentate and edentulous community-dwelling older adults. J Am Geriatr Soc 2006; 54:1701-12.

12. Hugo FN, Hilgert JB, Sousa ML, Silva DD, Pucca Jr. GA. Correlates of partial tooth loss and edentulism in the Brazilian elderly. Community Dent Oral Epidemiol 2007; 35:224-32.

13. De Marchi RJ, Leal AF, Padilha DM, Brondani MA. Vulnerability and the psychosocial aspects of tooth loss in old age: a Southern Brazilian study. J Cross Cult Gerontol 2012; 27:239-58.

14. Rizzo VM, Kintner E. The utility of the behavioral risk factor surveillance system (BRFSS) in testing quality of life theory: an evaluation using structural equation modeling. Qual Life Res 2013; 22: 987-95.
15. Orfila F, Ferrer M, Lamarca R, Tebe C, DomingoSalvany A, Alonso J. Gender differences in healthrelated quality of life among the elderly: the role of objective functional capacity and chronic conditions. Soc Sci Med 2006; 63:2367-80.

16. Hilgert JB, Hugo FN, Sousa MDAL, Bozzetti MC. Oral status and its association with obesity in Southern Brazilian older people. Gerodontology 2009; 26:46-52.

17. World Health Organization. Oral health surveys: basic methods. $4^{\text {th }}$ Ed. Geneva: World Health Organization; 1997.

18. Slade GD. Derivation and validation of a shortform oral health impact profile. Community Dent Oral Epidemiol 1997; 25:284-90.

19. Santos CM, Oliveira BH, Nadanovsky P, Hilgert JB, Celeste RK, Hugo FN. The Oral Health Impact Profile-14: a unidimensional scale? Cad Saúde Pública 2013; 29:749-57.

20. Kline P. An easy guide to factor analysis. London: Routledge; 1994.

21. Schermelleh-Engel K, Moosbrugger H, Müller H. Evaluating the fit of structural equation models: tests of significance and descriptive goodness-offit measures. Methods of Psychological Research Online 2003; 8:23-74.

22. Byrne BM. Structural equation modeling with Mplus: basic concepts, applications, and programming. London: Routledge Academic; 2012.

23. Bentley JP, Brown CJ, McGwin Jr. G, Sawyer P, Allman RM, Roth DL. Functional status, life-space mobility, and quality of life: a longitudinal mediation analysis. Qual Life Res 2013; 22:1621-32.

24. Sousa KH, Kwok OM. Putting Wilson and Cleary to the test: analysis of a HRQOL conceptual model using structural equation modeling. Qual Life Res 2006; 15:725-37.

25. Schulz T, Niesing J, Stewart RE, Westerhuis R, Hagedoorn M, Ploeg RJ, et al. The role of personal characteristics in the relationship between health and psychological distress among kidney transplant recipients. Soc Sci Med 2012; 75:1547-54.

26. Moi AL, Nilsen RM. Pathways leading to self-perceived general health and overall quality of life in burned adults. Burns 2012; 38:1157-64.

27. Halvorsrud L, Kirkevold M, Diseth A, Kalfoss M. Quality of life model: predictors of quality of life among sick older adults. Res Theory Nurs Pract 2010; 24:241-59.

28. Andrade FB, Lebrão ML, Santos JLF, Duarte YAO, Teixeira DSC. Factors related to poor self-perceived oral health among community-dwelling elderly individuals in São Paulo, Brazil. Cad Saúde Pública 2012; 28:1965-75.

29. Manrique-Espinoza B, Salinas-Rodriguez A, Mojarro-Iniguez MG, Téllez-Rojo MM, Pérez-Núñez $R$, Ventura-Alfaro CE. Tooth loss and dental healthcare coverage in older rural Mexican adults living in poverty. J Am Geriatr Soc 2010; 58:804-5. 
30. Jain M, Kaira LS, Sikka G, Singh S, Gupta A. Sharma R, et al. How do age and tooth loss affect oral health impacts and quality of life? A study comparing two state samples of gujarat and rajasthan. J Dent (Tehran) 2012; 9:135-44.

31. Martins AB, Santos CM, Hilgert JB, Marchi RJ, Hugo FN, Padilha DMP. Resilience and self-perceived oral health: a hierarchical approach. J Am Geriatr Soc 2011; 59:725-31.
32. Tsakos G, Sheiham A, Iliffe S, Kharicha K, Harari D, Swift CG, et al. The impact of educational level on oral health-related quality of life in older people in London. Eur J Oral Sci 2009; 117:286-92.

Submitted on 10/Aug/2014

Final version resubmitted on 19/Mar/2015

Approved on 30/Mar/2015 